\title{
Stromal keratitis
}

\author{
INSERM
}

\section{Source}

INSERM. (1999). Orphanet: an online rare disease and orphan drug data base. Stromal keratitis. ORPHA:137599

Herpes simplex (HSV) stromal keratitis is an infectious ocular disease of either necrotizing or non-necrotizing form, due to an HSV infection, and characterized by corneal stromal necrosis, inflammation, ulceration and infiltration by leukocytes. Corneal perforation and blindness can also occur in severe cases. 